\title{
O empresário schumpeteriano e o setor de varejo no Brasil: Samuel Klein e as Casas Bahia
}

\author{
Armando João Dalla Costa ${ }^{1}$ \\ Junior Ruiz Garcia ${ }^{2}$
}

Resumo: O comportamento do empresário schumpeteriano, freqüentemente, é analisado sob o contexto da produção industrial, sendo restritos os estudos que definem sua função no setor comercial. Este trabalho tem por objetivo encontrar os elementos que caracterizam um empresário inovador sob a perspectiva schumpeteriana na atividade comercial. De acordo com Schumpeter, empresário é o agente que leva a cabo novas combinações de fatores disponíveis na economia. Essas novas combinações são denominadas inovações e podem manifestar-se em cinco circunstâncias: i) novos produtos ou melhoria de produtos existentes, ii) novo método de produção, iii) novo mercado, iv) nova fonte de matéria-prima, e v) uma nova organização da indústria. Com base nestas definições e informações sobre o comportamento de Samuel Klein, fundador das Casas Bahia, empresa do setor de varejo de eletroeletrônicos no Brasil, se buscará identificar as características do empresário inovador. O estudo envolve uma revisão da literatura, seguida de estudo do setor de varejo brasileiro e finalmente uma análise da história da empresa e do empresário sob o enfoque proposto.

Palavras-chave: empresário schumpeteriano; Casas Bahia; varejo; eletroeletrônicos.

\footnotetext{
1 Doutor pela Université de la Sorbonne Nouvelle Paris III. Professor no Programa de Pós Graduação em Desenvolvimento Econômico da UFPR e coordenador do NUPEM - Núcleo de Pesquisa em Economia Empresarial. E-mail: ajdcosta@ufpr.br

2 Economista pela UFPR, membro do NUPEM, participou do programa de Iniciação Científica da UFPR, bolsista do CNPq. E-mail: jrgarcia1989@yahoo.com.br
} 


\title{
A Schumpeterian entrepreneur and the retail sector in Brazil: Samuel Klein and Casas Bahia
}

\begin{abstract}
Since the behaviour of a Schumpeterian entrepreneur is frequently analysed in the context of industrial production, little work has been done about his position in the commercial sector. This paper aims at identifying elements which are typical of a Shumpeterian entrepreneur able to innovate in trade activities. According to Schumpeter, entrepreneur is a agent that carries out new combinations of assets available in the economy, which are called innovations, under five circumstances: i) new products or improvement of existing ones, ii) new producing methods, iii) new markets, iv) new sources of raw material, $v$ ) new industrial organisation. Based on this framework, the behaviour of Samuel Klein, founder of Casas Bahia, a retail company, selling white goods, is discussed in the light of what best describes an innovative entrepreneur. Beside a review of the literature related to the subject, the Brazilian retail sector and the history of Casas Bahia and its owner are analysed under the above mentioned approach.
\end{abstract}

Key words: Schumpeterian entrepreneur; Casas Bahia; retail; white goods.

JEL: M12, M13, M54.

\section{Introdução}

O empresário schumpeteriano é analisado na teoria econômica como o agente capaz de promover o desenvolvimento econômico. Entretanto, estudos referentes à contribuição do empresário inovador estão restritos aos seus impactos na perspectiva macroeconômica, enquanto que sua participação dentro da empresa é deixada de lado pela teoria schumpeteriana. A teoria faz uma análise do empresário inovador no contexto geral da economia. Não adota nenhum ramo de atividade específico para analisar o comportamento desse agente. Deste modo, caberia perguntar como o empresário inovador utilizaria suas habilidades numa empresa comercial? O objetivo deste trabalho é identificar alguns elementos que caracterizam o agente inovador em uma empresa varejista específica.

As Casas Bahia é uma empresa do setor varejista brasileiro do segmento de eletroeletrônicos que, criada e sob a gestão de Samuel Klein, saiu do anonimato para emergir no século XXI como a maior rede de varejo de eletroeletrônicos. Observa-se desde a sua fundação o uso de estratégias freqüentemente contrárias à tendência do setor, como o comportamento arrojado do fundador que indicou a presença de características definidoras de um empresário schumpeteriano. 
A empresa passou pelas diversas crises presenciadas pela economia brasileira a partir da década de 1970 . Diferente da própria situação econômica e de suas concorrentes, as Casas Bahia não só sobreviveu, mas cresceu continuamente nos últimos trinta anos, até ocupar o primeiro lugar entre as empresas do setor.

Este trabalho destaca os principais elementos na gestão da empresa que contribuíram para o ritmo de crescimento apresentado nos últimos anos. A análise busca estabelecer um paralelo entre a teoria do empresário inovador e o comportamento de Samuel Klein na direção das Casas Bahia.

O enfoque está distribuído em quatro seções. A primeira resgata as bases teóricas que explicam o empresário inovador. A segunda apresenta as características do setor varejista no Brasil. A terceira traz a história das Casas Bahia e de seu fundador, além da análise comparativa entre o empresário schumpeteriano e o comportamento de Samuel Klein à frente da empresa.

\section{Elementos teóricos sobre o empresário schumpeteriano}

A figura do empresário foi discutida na teoria econômica sob diversas abordagens segundo as percepções dos economistas. A teoria neoclássica não se preocupou em analisar, de modo específico, o papel do empreendedor, pelo fato desta abordagem adotar como pressuposto a racionalidade dos agentes econômicos na utilização das informações necessárias para a tomada de decisão (Bêrni \& Corrêa 2005). No caso da determinação da oferta, por exemplo, a produção e os preços são determinados pelas curvas de custos e receitas marginais, das quais se deriva a maximização do lucro. No entanto, abordagens mais heterodoxas reconhecem o papel e a importância do empresário na atividade econômica.

O economista americano Frank Knight reconhece o papel do empresário, ao qual, atribui a função de previsão dos acontecimentos que resultam na tomada de decisões que conduzem ao lucro extraordinário. Para o autor (citado por Bêrni \& Corrêa 2005) os empresários se diferenciam dos demais indivíduos pela capacidade de previsão na tomada de decisão.

Em seu texto clássico The nature of the firm ("A natureza da firma") o economista Ronald Coase (1937) defende que as firmas existem como uma forma particular de organização econômica, um "arranjo institucional" alternativo ao mercado. De acordo com Coase, a firma é observada como um sistema de relações construídas a partir do mo- 
mento em que o empresário assume a responsabilidade pela alocação dos recursos disponíveis à produção. O empresário é aquele agente que conduz as transações da firma e, num sistema competitivo, retira do mecanismo de preços e evoca para si a responsabilidade pela alocação dos recursos.

Edith Penrose (1995) também atribui particular importância ao empresário, defendendo-o como agente de uma forma diferente das abordagens até então formuladas na teoria econômica. A autora o definiu como o empreendedor que presta serviços às operações da firma, relacionadas à introdução de idéias, enfatizando aquelas associadas a produtos, localização, tecnologia, organização administrativa e aquisição de recursos.

O termo empresário (...) é usado num sentido funcional para se referir a indivíduos ou grupos dentro da firma fornecendo serviços empresariais, qualquer que seja sua posição ou classificação ocupacional. Serviços empresariais são aquelas contribuições para operações da firma que se relacionam à introdução e aprovação no interesse da firma de novas idéias, particularmente com respeito a produtos, localização e significantes mudanças tecnológicas, para a aquisição de novo pessoal administrativo, fundamentais mudanças na organização administrativa da firma, aumento de capital, e para elaborar novos planos de expansão, incluindo a escolha dos métodos de expansão.(Penrose 1995:31-2).

Os empresários também podem ser considerados como uma categoria industrial altamente especializada na visão marshalliana, que considera-os como intermediários entre o trabalhador manual e o consumidor (Marshall 1985). Nesta visão, observa-se uma proximidade entre seus conceitos e os de Schumpeter (1982), para o qual o empresário pode ser visto como um intermediário entre a inovação e o mercado. Admitindo-se que a inovação decorre de processos manuais, caracteriza-se uma aproximação na conceituação dos autores mencionados. Todavia, para Marshall o empresário assume uma postura mais de administrador do que aquele agente que busca remodelar o processo no qual a empresa está inserida. "O crescimento da empresa implica na necessidade de delegar a seus principais subordinados responsabilidades cada vez maiores, em parte porque o trabalho a ser feito é cada vez mais complexo ..." (Marshall 1985:256). De acordo com Schumpeter (1982), a função de empresário não pode ser herdada, e deste modo, a delegação das responsabilidades à qual Marshall se refere indica que o empresário tem uma função mais direcionada à administração da empresa do que a promover uma modificação na estrutura. Neste ponto ocorre a diferenciação entre os estudos dos autores acima citados. 
Contudo, é na análise schumpeteriana que o empresário foi tratado de forma particular na teoria econômica. O empresário, segundo Schumpeter (1982), assume um papel central no processo de inovação e, conseqüentemente, no desenvolvimento econômico. Como resultado de sua ação na economia surgem as inovações em diversas indústrias. Para o autor, a função do empresário é reformar ou revolucionar o padrão de produção através da: i) exploração de uma invenção, ii) implementação de uma possibilidade que ainda não tenha sido experimentada na produção de uma nova mercadoria, e iii) produzir um bem já existente com alterações no processo de fabricação. Cabe ao empresário promover a ampliação dos mercados, tanto para produtos como para novas fontes de insumos. Dito de outra forma, cabe ao empresário realizar uma ampliação da oferta de recursos ou da demanda para as mercadorias, assim como implementar uma nova organização na indústria (Schumpeter 1984:173).

A inovação significa combinar materiais e/ou organizar as forças produtivas que estão ao alcance dos agentes de maneiras diferentes, para produzir outras mercadorias, ou as mesmas através da utilização de novos métodos. Em outras palavras, inovação é a ação de combinar diferentemente os materiais e forças produtivas disponíveis na economia, a fim de viabilizar a produção de novos produtos. Este conceito de inovação manifesta-se em cinco circunstâncias: i) por meio de um novo bem ou serviços, ou de uma nova qualidade de uma mercadoria, ii) introdução de um novo método de produção; iii) um novo mercado; iv) uma nova fonte de oferta de matéria-prima, ou de bens semimanufaturados e; v) uma nova organização de qualquer indústria (Schumpeter 1982:48).

A realização de novas combinações significa, portanto, o emprego diverso dos meios produtivos existentes na economia. Os diferentes métodos de emprego e não a poupança e os aumentos de quantidade disponível de mão-de-obra, alteraram a estrutura do mundo econômico nos últimos cinqüenta anos. Schumpeter (1982) denomina as novas combinações de "empreendimento", nos quais os empresários exercem a função de pôr em prática as inovações (Possas 1987:175). Portanto, o sucesso do empreendimento depende da intuição e da capacidade do empresário em ver as coisas de uma maneira diferente dos demais agentes da economia. O sucesso desta percepção é posteriormente corroborado pelos fatos que a princípio não estavam claros naquele momento (Schumpeter 1982:85).

As novas possibilidades estão disponíveis no ambiente, em particular as descobertas, e continuamente acrescentadas ao conhecimento existente. Na sociedade existem pessoas que são capazes de criar novos produtos, mas que não conseguem colocar seu invento no mercado, ou 
seja, viabilizá-lo como produto de consumo. Neste ponto é que o empresário emprega suas habilidades, pois ele sabe como pôr este novo produto no mercado, como fazer a ligação entre o inventor e o consumidor. Para isso: o empresário busca aperfeiçoar processos, ampliar mercados e alterar a organização industrial para colocar em prática este invento (Schumpeter 1984:173). Um invento só se transforma em inovação quando o resultado da invenção tem utilidade no mercado e seja passível de comercialização.

O empresário inovador não precisa, necessariamente, ser proprietário do capital e nem mesmo um gerente da firma. Torna-se inovador ao viabilizar as invenções através da iniciativa e dos esforços da empresa em que atua. Num primeiro momento, inovação consiste em produzir uma nova mercadoria. Em seguida, o empresário inovador empenha-se em gerar novas necessidades no mercado consumidor. Significa que ele busca atribuir uma utilidade ao invento, que passa a ser útil no mercado. Os consumidores serão por ele "ensinados" a demandar produtos ou serviços novos ou que se diferenciem em um aspecto ou outro daqueles que tinham o hábito de usar (Schumpeter 1982:84-5).

Observa-se que a função de empresário não pode ser herdada como a função de capitalista, quando um indivíduo pode nascer proprietário do capital. A história mostra a dificuldade de se formar "empresários schumpeterianos" que possam conduzir as empresas, independentemente de serem proprietários ou não de seus negócios. Além disso, o empresário inovador é um tipo especial de agente, característica atribuída ao seu comportamento diante das possibilidades. Essa habilidade o torna a força motriz de um grande número de fenômenos significativos na economia. O comportamento diferenciado deste agente será observado pela classe empresarial que absorverá o "empresário schumpeteriano" e a sua família para controlar seus empreendimentos. Essas classes empresariais utilizam a capacidade do empresário para revitalizar permanentemente o empreendimento familiar, enquanto que, ao mesmo tempo, as famílias capitalistas rompem sua relação ativa dentro da empresa deixando-a após uma ou duas gerações (Schumpeter 1982:56).

...alguém só é empresário quando efetivamente "levar a cabo novas combinações", e perde esse caráter assim que tiver montado o seu negócio, quando se dedicar a dirigi-lo, como outras pessoas dirigem seus negócios. Essa é a regra, certamente, e assim é tão raro alguém permanecer sempre como empresário através das décadas de sua vida ativa, quanto é raro um homem de negócios nunca passar por um momento em que seja empresário, mesmo que seja em menor grau. 
O desempenho da atividade de viabilização das inovações, assumida pelo empresário, resulta freqüentemente no contato com situações desconhecidas e incertas. Aquilo que para todo indivíduo envolvido no fluxo circular é evidente, rotineiro, torna-se para o inovador uma incógnita (Paula et al. 2004:12). Para Schumpeter, o empresário não é aquele que corre riscos: "o risco obviamente recai sobre o proprietário dos meios de produção ou do capital-dinheiro que foi pago por eles, portanto nunca sobre o empresário. (...) O empresário nunca é aquele que corre o risco" (Schumpeter 1982:92).

Conseqüentemente, a função de empresário na teoria schumpeteriana está associada à necessidade de crédito ad hoc. Neste caso, o capital é considerado como a soma dos meios de pagamento que estão disponíveis em dado momento para a transferência aos empresários. O desempenho da função de empresário requer a disponibilidade de capital em montante suficiente para financiar as inovações no mercado. Segundo o autor, o capital nada mais é do que a alavanca com a qual o empresário subjuga ao seu controle os bens concretos de que necessita, nada mais do que um meio para se desviar os fatores de produção para novos usos ou de ditar uma nova direção para a produção (Schumpeter 1982:71$80)$.

A função de empresário pode ser vista sob diversas perspectivas na teoria econômica e dentro de diferentes setores, por exemplo, no setor comercial. Na teoria econômica, cada autor define o papel do empresário na dinâmica do desenvolvimento econômico de acordo com definições pré-estabelecidas. Dentre as abordagens apresentadas, a mais compatível ao presente estudo é a do "empresário schumpeteriano". Segundo Schumpeter (1982:55), “... a função de empresário deve sempre aparecer na dinâmica econômica combinada a diversos tipos de atividades ...”. Como conseqüência, caberiam diferentes tipos de inovação na atividade econômica: em produtos, processos e serviços. Esta abordagem se concentra em analisar o empresário dentro do setor produtivo da economia, pouco se discute na teoria schumpeteriana a função do empresário na atividade comercial. Diante das afirmações teóricas, qual seria o tipo de inovação inerente ao setor de varejo ou a atividade comercial?

\section{Características estruturais do mercado varejista de eletroeletrônicos}

A atividade varejista integra funções como a procura, seleção, aquisição, distribuição, comercialização e entrega dos produtos. Algumas lojas estendem suas atividades à assistência técnica, designada em anos 
recentes, como "serviço pós-venda". A mudança nas atribuições do setor varejista está relacionada à estratégia das empresas de ampliar sua participação no mercado. O setor é considerado um grande demandante de mão-de-obra na economia de qualquer país, no entanto, emprega trabalhadores menos qualificados em relação aos que trabalham na produção industrial. Essa tendência está se revertendo com a ampliação da utilização de sistemas de distribuição informatizados, exigindo uma mãode-obra mais qualificada. Outra característica do setor está relacionada à alta suscetibilidade às variações ou mudanças no rumo das políticas públicas, que reflete diretamente na estratégia de marketing das empresas varejistas (BNDES 1996; FGV 2003).

A título de contextualização histórica, antes de 1980 o varejo brasileiro apresentava as seguintes características: i) estrutura de mercado regional com poucas lojas de nível nacional, ii) relacionamento restrito ao âmbito comercial, iii) ausência de padronização no fluxo das mercadorias dentro das empresas, iv) predominância das gestões familiares, v) intensivo em mão-de-obra, vi) informalidade nas operações, vii) freqüentes indefinições do foco e elevado endividamento de algumas empresas. Com a abertura da economia na década de 90 o setor sofreu muitas transformações na estrutura de mercado tais como o aumento na concorrência, alterações no padrão de consumo e novas políticas públicas para o setor (BNDES 1996).

A abertura comercial possibilitou a entrada de produtos importados no mercado doméstico, causando aumento da concorrência no setor varejista. A indústria local não estava preparada para competir com os produtores estrangeiros, condição que impôs a necessidade de profundas transformações nas empresas varejistas. O governo implementou, em 1994, um novo plano de estabilização que resultou no aumento relativo do poder de compra da população, estimulando o setor varejista a buscar uma maior eficiência e novos mercados, aumentando, dessa forma, a disputa no setor pelos consumidores das classes C, D e E. A resposta a essa tentativa de estabilização da economia se manifestou através da expansão do consumo. Contudo, a indústria nacional também não estava preparada para atender à nova demanda, gerando pressões sobre o nível de preços da economia. O governo, para conter o consumo, adotou certas medidas (restrição ao crédito, manutenção de elevadas taxas de juros e redução das tarifas de importação) e o aumento na inadimplência que se seguiu afetou diretamente as empresas varejistas. As medidas governamentais resultaram no fechamento de lojas, redução do quadro de funcionários, informatização das redes de distribuição e das lojas, alterações no mix de produtos, profissionalização da gestão, abertura de capital de algumas empresas (Ponto Frio e Arapuã), maior giro dos produtos, busca por uma maior capitalização do setor, 
retomada dos instrumentos de planejamento e troca de comando nas principais redes de varejo (BNDES 1996).

Levantamento da FGV (2003) identificou que as empresas do setor no Brasil representavam cerca de $84,5 \%$ do total de empresas comerciais, com um faturamento de aproximadamente 173 bilhões de reais em 2000, que representou $38,4 \%$ do faturamento total do setor, além de ser responsável por $73,3 \%$ do emprego gerado na atividade comercial. Mesmo com a elevada instabilidade da economia brasileira no início da década de 90, o setor comercial ampliou sua participação no PIB.

TABELA 1. PARTICIPAÇÃO SEGUNDO CATEGORIAS DO COMÉRCIO: 2002 (EM \%)

\begin{tabular}{lcccc}
\hline \multicolumn{1}{c}{ Categorias do comércio } & $\mathrm{N}^{\circ}$ de empresas & Emprego & Salários & Receita Líquida \\
\hline Comércio por atacado & 6,9 & 13,5 & 23,3 & 42,5 \\
Comércio varejista & 85,3 & 77,8 & 66,0 & 45,5 \\
Comércio de veículos e peças & 7,8 & 8,7 & 10,7 & 12,0 \\
Total & 100,0 & 100,0 & 100,0 & 100,0 \\
\hline
\end{tabular}

FONTE: Elaboração dos autores, a partir de IBGE - Pesquisa Anual de Comércio 2002.

As empresas especializadas no comércio de eletroeletrônicos têm apresentado nos últimos anos uma acelerada expansão geográfica, resultado da estratégia de aquisição adotada pelas grandes redes, tendo como conseqüência a concentração das vendas em determinados grupos de alcance nacional (BNDES 1996; 2005). Esse movimento de concentração resulta na elevação do poder dos varejistas frente às negociações com fornecedores, promovendo vantagens como: elevação nos prazos de pagamento, redução de preços, garantia de pontualidade e uma melhora na qualidade das mercadorias. Registram-se também neste período projetos de expansão com dimensão estadual e regional das empresas (Padilha 2004).

De acordo com as estratégias adotadas pelo varejo de eletroeletrônicos na década de 1990, o processo de concentração continua sendo a forma mais rápida de expansão. Isto se observa, sobretudo nos últimos anos, com a concentração verificada no varejo, hoje dominado por algumas poucas grandes redes (Panorama Setorial 2005). O mercado brasileiro está atualmente dividido entre cinco grandes redes de varejo: Lojas Colombo, Lojas Cem, Magazine Luiza, Ponto Frio e Casas Bahia. 
TABELA 2. PRINCIPAIS EMPRESAS: QUANTIDADE DE LOJAS/ FATURAMENTO: 1994-2003 (EM MIL REAIS)

\begin{tabular}{lcccc}
\hline \multicolumn{1}{c}{ EMPRESA } & LOJAS* $^{*}$ & ROL $^{1}$ & ROL $^{2}$ & REGI $\tilde{O}$ \\
\hline Casas Bahia** & 396 & 494,20 & $37.200,56^{3}$ & DF, GO, MG, MS, PR, RJ, RS, SC e SP. \\
Ponto Frio & 340 & 494,53 & $-7,45$ & RJ, ES, MG, DF, GO, MT, SP, PR, SC e RS. \\
Lojas Colombo & 361 & 258,20 & 25,38 & PR, SC, RS, SP e MG. \\
Magazine Luiza & 408 & n.d. & 24,65 & GO, MS, PR, SP e MG. \\
Lojas Cem & 250 & 128,20 & 29,44 & SP, MG, RJ e PR. \\
\hline
\end{tabular}

FONTE: Elaboração dos autores a partir de Gazeta Mercantil, Lojas Colombo, Lojas Cem, Magazine Luiza, Ponto Frio e Casas Bahia.

NOTAS: * final de 2004; ** final de 2002; 1 Resultado Operacional Líquido em 1994; 2 Resultado Operacional Líquido em 2003; 3 Resultado em 2002.

O setor varejista também é altamente influenciado pela disponibilidade de crédito na economia, reflexo da preferência da população em realizar suas compras a prazo. Deste modo, a maior parte das empresas passou a oferecer crediário próprio ao cliente (inclusive no setor alimentício) ${ }^{3}$, aumentando assim a demanda de recursos para suprir as novas modalidades de financiamento. Neste processo, para aumentar seu capital de giro, as lojas iniciaram parcerias com instituições financeiras (Gazeta Mercantil 2004).

As novas modalidades de crédito ao consumidor, com juros reduzidos, aceleraram a retomada do crescimento do varejo depois da última eleição presidencial. Em 2003, o aumento no volume de crédito à pessoa física totalizou aproximadamente 74,7 bilhões de reais (Padilha, 2004). $\mathrm{O}$ aumento na disponibilidade de crédito e novas modalidades de financiamento contribuíram para o crescimento no volume de vendas do setor.

GRAFICO 1. DESEMPENHO DO COMÉRCIO VAREJISTA (VOLUME DE VENDAS $)^{*}: 2003 / 2005$

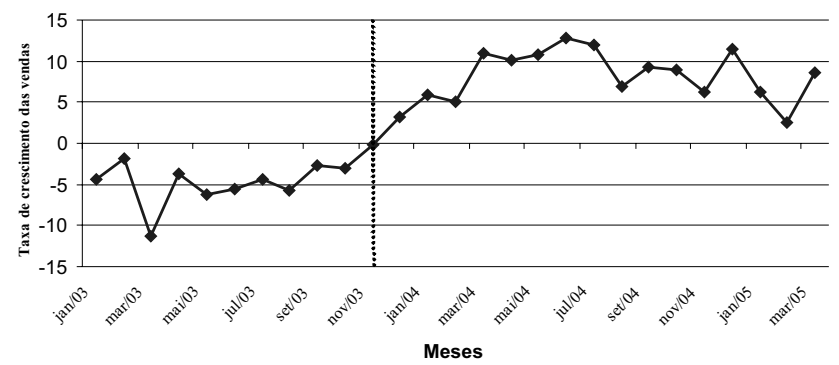

FONTE: IBGE-PMC (Pesquisa Mensal de Comércio).

NOTAS: * mês/ igual mês anterior. Elaboração própria.

3 Os supermercados adotaram na década de 90 o cartão exclusivo possibilitando a compra de produtos alimentícios a prazo. 
Os investimentos em publicidade totalizaram 23,4 bilhões de reais em 2003 representando um aumento de $18 \%$ em relação a 2002. O varejo é a atividade econômica que mais tem investido em propaganda nos últimos anos no Brasil. Do valor total dos investimentos em mídia, o varejo investiu cerca de 6,9 bilhões de reais, o que corresponde a um aumento, em relação a 2002, de 34\%. O segundo setor que mais investiu em mídia em 2003 foi o de serviços ao consumidor ${ }^{4}$, que apresentou uma cifra de 2,1 bilhões de reais com crescimento em relação a 2002 de $11 \%$. Os meios de comunicação mais utilizados pelos anunciantes foram: televisão (10,8 bilhões de reais), jornal ( 7,8 bilhões de reais), revista $(2,2$ bilhões de reais) e televisão por assinatura (1,5 bilhões de reais). Esses canais concentram 95\% dos gastos em propaganda no Brasil (Pereira 2004). A ampliação dos investimentos em mídia pelo setor varejista modificou a estrutura de competição entre as empresas de propaganda.

$\mathrm{O}$ crescimento dos investimentos em publicidade e o poder de compra das redes mudaram completamente a estrutura de mercado. O setor de varejo que era pouco concentrado passa a assumir em determinadas regiões do país as características de um oligopólio. Esta modificação da estrutura dificulta a entrada de novas empresas. As barreiras podem contribuir para a geração e consolidação de um mercado fechado e dominado pelas grandes empresas. Por outro lado, este processo pode ser favorável ao consumidor, uma vez que a presença de grandes empresas no varejo de eletroeletrônicos e a participação de outros segmentos como os supermercados garantem a manutenção do ambiente concorrencial.

\section{Uma análise das Casas Bahia: fundador, empresa e empresário schumpeteriano}

Caracterizado o empresário, agente econômico que incorpora as inovações, tem-se os elementos necessários para uma análise comparativa. O empresário destaca-se dos outros indivíduos pela capacidade empreendedora em levar a cabo novas combinações, ou seja, de ver as coisas de maneira diferente dos demais agentes da economia. O resultado desta percepção é posteriormente corroborado pelos fatos que a princípio não estavam claros no momento que ele empreende uma inovação no mercado (Schumpeter 1982).

A seguir é feita uma análise comparativa sobre o empresário schumpeteriano no varejo brasileiro representado pelo fundador das Casas Bahia, Samuel Klein. Esta parte do trabalho está dividida em três

4 Representa as atividades de transporte coletivo e carga, locações, cursos, alimentação, saúde, segurança, etc. 
subseções. A primeira destaca a história de Samuel Klein na Europa. A segunda apresenta informações referentes à década de 1950-1970 da empresa e do empresário varejista, enquanto que a terceira trata da empresa e do empresário na década de 1980 - 1990. A última discute a empresa e o empresário no século XXI.

\subsection{Samuel Klein: empresário inovador}

A função de empresário, segundo a perspectiva schumpeteriana, não pode ser herdada, isto é, um indivíduo não transfere sua capacidade de "levar a cabo novas combinações" a seus descendentes (Schumpeter 1982). Desse modo, o sujeito nasce com os elementos que caracterizam um empresário schumpeteriano. Durante sua vida, os elementos são aperfeiçoados e colocados em prática diante das possibilidades oferecidas pelo ambiente.

A biografia empreendida pelo jornalista, Elias Awad ${ }^{5}$ apresenta informações sobre Samuel Klein e sua trajetória na consolidação como empresário inovador. Nascido na Polônia, em 15 de novembro de 1923, filho de Sucher e Szeva Klein, começou a trabalhar com o pai ainda na infância. Quando criança, apresentou uma "vocação natural" para o comércio. Aos onze anos já havia desenvolvido a capacidade de compra e venda de algumas mercadorias. As habilidades como comerciante evidenciaram-se quando foi encarregado pelo pai da compra de bezerros para a família. Com esta incumbência, percorria as vilas próximas na tentativa de adquirir as mercadorias pelo preço menor. Assim, a compra dos animais poderia representar uma fonte extra de renda, pois no retorno, freqüentemente, comercializava alguns dos bezerros com certo lucro (Awad 2005:16-31).

Observa-se, desde o início, que o atual empresário já apresentava capacidade de empreender as possibilidades oferecidas pelo ambiente econômico (Schumpeter 1984:173). Este elemento caracteriza uma fração dos quesitos que o empresário schumpeteriano tem no exercício de sua função.

Quando da invasão da Polônia pelos alemães na II Guerra Mundial, em novembro de 1939, a família Klein foi separada. Sua mãe e três irmãos morreram em campos de concentração em Treblinka, enquanto ele e o pai foram levados para o campo de concentração de Budzin na Polônia onde passou dois anos até a chegada dos soldados soviéticos (Awad 2005:33-48).

5 As informações deste capítulo foram retiradas da biografia de Samuel Klein. AWAD, E. Samuel Klein e Casas Bahia: uma trajetória de sucesso. 2. ed. São Paulo: Novo Século, 2005. 
O fim da guerra significou para Samuel Klein o retorno à atividade comercial. Inicialmente, vendia Vodka contrabandeada para os soldados soviéticos pelo dobro do preço de custo. A capacidade de ver as coisas de forma diferente levou-o a deixar a primeira atividade para direcionarse à comercialização das mercadorias em feiras livres próximas da cidade em que morava. No entanto, a descoberta de um estoque de açúcar, mercadoria altamente cotada no mercado europeu na ocasião do pósguerra, numa fábrica próxima que estava sob controle soviético, foi outro momento para tornar evidente suas habilidades. De posse de capacidade e intuição, características do empresário inovador, Samuel Klein conseguiu persuadir os soldados soviéticos a participar da venda do açúcar.

Para encontrar melhor lugar onde exercer suas habilidades comerciais, a família Klein ${ }^{6}$ mudou-se para Munique, uma vez que a Polônia estava destruída. Nessa cidade, passou a comercializar aspirinas Bayer da Alemanha para a Polônia, trazendo couro na viagem de volta. Enquanto esteve na Europa, Samuel Klein permaneceu no ramo de varejo vendendo tudo que lhe proporcionasse renda como açúcar, especiarias (vinho e queijo) e prata para a fabricação de talheres (Awad 2005:53-66).

Em dezembro de 1949, casou-se com Ana na cidade de Berlim e no dia 27 de novembro de 1950 nasceu Michael, o primeiro filho do casal ${ }^{7}$. Juntos iniciaram um novo empreendimento na cidade, a abertura de uma loja especializada em produtos finos: vinhos, queijos, amêndoas e outros produtos importados da Itália (Awad 2005: 67-75). A capacidade de buscar novas combinações (Schumpeter 1982) com os recursos disponíveis no ambiente, é outra característica que se destaca no empresário inovador, assim como a falta de recursos para o desenvolvimento dos empreendimentos. Como visto na revisão da teoria schumpeteriana, o empresário não precisa ser proprietário do capital para viabilizar as inovações. Samuel Klein, mesmo sem recursos próprios para colocar em prática suas idéias, conseguiu, por meio da "capacidade natural" reverter a situação.

Em dezembro de 1951, foi convidado a mudar-se para a América do Sul, embarcando no navio Provence, no porto de Gênova na Itália, rumo à Bolívia, onde chegou em fevereiro de 1952. Entretanto, contrário às informações que tinha sobre a região, o país estava em plena guerra civil. Percebendo o perigo que corria, decidiu ir para o Brasil, estabelecendo-se, de início, no Rio de Janeiro e, logo em seguida, transferiu-se

6 Nesta época a família estava se recompondo, os três irmãos que sobreviveram à guerra tinham se reencontrado e estava em busca do pai que também sobreviveu ao campo de concentração.

7 Além deste, o casal ainda teve os seguintes filhos: Saul (1954), que significa Sucher; Eva (1955) e Oscar (1957), todos nascidos em São Caetano do Sul. Este último morreu aos 18 anos, num acidente de carro (Awad 2005). 
para a cidade São Paulo. No Bom Retiro, bairro da região central, conhecido pela grande concentração de Judeus, Samuel Klein entrou em contato com alguns patrícios que atuavam com estabelecimentos comerciais, a fim de encontrar trabalho (Awad 2005:79-89). Observa-se em Samuel Klein a constante busca em empreender novas combinações, no início de forma restrita à subsistência e, posteriormente, elevando de forma considerável a renda decorrente da atividade comercial.

\subsection{A empresa e o empresário na década de 1950-1970}

O retorno de Getúlio Vargas ao poder foi marcado por uma estratégia de desenvolvimento econômico alternativo para o país. O primeiro governo Vargas contribuiu para o processo de transferência do setor dinâmico da economia, da produção agroexportadora para a Substituição de Importação, ou seja, o início da industrialização. A continuidade dessa mudança na dinâmica da economia abriu novas oportunidades de desenvolvimento para o país e a cidade de São Paulo estava no centro desta transformação (Abreu 1989).

De fato as possibilidades estavam presentes a todo o momento, faltava saber como aproveitá-las. Samuel Klein sabia como desenvolver as oportunidades que lhe apareciam nesta nova fase da vida. A primeira atitude foi encontrar algum meio de utilizar suas habilidades de comerciante. Em São Caetano do Sul, por meio de um amigo, entrou em contato com o senhor Nulman, um mascate ${ }^{8}$ que estava se aposentando, do qual comprou a casa comercial, uma charrete e o cadastro de 200 clientes (Awad 2005:89-92).

No primeiro dia de trabalho, decidiu visitar cliente por cliente, mas encontrou dificuldade com o idioma. Por outro lado, tinha grande habilidade em lidar com o comércio, ou seja, era muito persuasivo. Para o fundador das Casas Bahia, o mais importante era que além de pagar o "financiamento" o cliente comprasse mais produtos. A maior parte dos clientes era composta por pessoas de baixa renda que tinham um único objetivo na compra das mercadorias, o de saber o valor da parcela do financiamento. Enquanto os concorrentes não concediam créditos às pessoas que aparentemente não tinham condições de honrar o compromisso, Samuel Klein adotou uma postura contrária. O resultado foi que em cinco anos o negócio apresentou um crescimento acima de todas as expectativas. $\mathrm{O}$ número de clientes que inicialmente era de 200 passou para 5 mil, além da contratação de cinco funcionários (Awad 2005: 92100). A evidência do empresário inovador nas decisões de Samuel Klein 
mostra como a ampliação do mercado (Schumpeter 1984:173), através da concessão de crédito, mostrou ser o elemento de sucesso do empreendimento, diferente das empresas concorrentes que não perceberam esta possibilidade.

A estratégia de fornecer crédito continuava a ser a melhor opção, por conseguinte, a elevação nas vendas se manteve acima da média da economia local. Deste modo, em novembro de 1957, Samuel comprou uma loja chamada "Casa Bahia", localizada na rua Conde Matarazzo, 567, cujo proprietário era Aarão Wasserman, com cerca de 800 clientes cadastrados. Contudo, as vendas externas foram mantidas. A abertura de um ponto fixo para a comercialização das mercadorias exigia uma nova estratégia na condução do negócio. Num curto espaço de tempo, o faturamento chegou a cerca de dois mil dólares por mês. O sucesso do novo empreendimento foi atribuído ao conhecimento adquirido nos cinco anos como mascate (Awad 2005:101-109). A capacidade de reconhecer as possibilidades que estão no ambiente é uma característica de Samuel Klein. O empresário schumpeteriano em parte é explicado por esta capacidade de identificar e explorar ao máximo uma nova combinação (Schumpeter 1984:173).

A pontualidade e o potencial de crescimento que os fornecedores perceberam na figura de Samuel Klein refletiram-se nas negociações. Os fornecedores passaram a fazer visitas e disputar os espaços existentes na "Casa Bahia": alguns chegavam a colocar placas para mostrar que seus produtos poderiam ser encontrados na loja. O empresário reconheceu, novamente, a possibilidade de ampliação do empreendimento através da negociação de grandes quantidades de mercadorias e em parcerias publicitárias com fornecedores. Quando a utilização do empreendimento chegou a plena capacidade, o empresário percebeu a necessidade de expandir as lojas. A abertura de uma filial destaca a habilidade do agente frente às necessidades de mudança (Awad 2005:109-10).

Na década de 1960, o país atravessava momentos críticos na política, a inflação e a elevação da dívida pública contribuíram para a desestabilização da economia. Entretanto, a "Casa Bahia" continuava em plena expansão. Em 1964, o Brasil estava sob o comando dos militares, mas no dia 15 de novembro foi inaugurada a primeira grande loja da futura rede, localizada na Rua Conde Francisco Matarazzo, 537, em São Caetano do Sul. A implementação de novos produtos e o investimento em outros segmentos do varejo, como a comercialização de eletrodomésticos, contribuiu para a diferenciação da nova loja. A compra de uma televisão com o intuito de verificar a aceitação do novo produto no 
mercado foi aprovada pelo consumidor, a mercadoria foi comercializada rapidamente. Diante desta situação, as previsões do empresário se confirmavam: investir em eletrodomésticos era um grande negócio (Awad 2005:113-15).

A entrada do filho Michael na empresa, em 1968, após iniciar o curso de Administração de Empresas, marcou uma nova fase para as Casas Bahia ${ }^{10}$. A complexidade do empreendimento estava exigindo a profissionalização da firma (Awad 2005:115-16) e o filho, com o conhecimento adquirido na faculdade e as relações com outros profissionais, veio colaborar neste novo momento.

No final de década de 1960, a falta de recursos para o financiamento das vendas impedia o potencial de crescimento. A solução foi a implantação do sistema de vendas financiadas, que exigia um aumento no capital de giro. Num primeiro momento os financiamentos de longo prazo foram repassados às financeiras. No entanto, a elevada taxa de juros tornou-se um empecilho à nova estratégia de expansão (Awad 2005:117). Neste momento, o empresário, que explora ao máximo uma nova combinação de fatores (Schumpeter 1984:173), se responsabiliza pela transferência dos valores financiados. A estratégia foi a seguinte: as Casas Bahia recebia o pagamento dos consumidores e comprometia-se a repassálos às financeiras. $\mathrm{O}$ resultado foi uma redução nas taxas de juros. Logo a rede passou a trabalhar com três financeiras simultaneamente (Awad 2005:117). Outra característica do empresário schumpeteriano fica evidente nesta estratégia. Para Schumpeter (1982), o empresário não precisa ser proprietário do capital para viabilizar novas combinações, e para isso busca novos mercados e altera a organização do processo para alcançar o resultado latente na visão inovadora do agente.

Contudo, a falta de capital ainda impedia o investimento em novas lojas. Samuel Klein percebia que a disponibilidade de recursos era um fator importante para o crescimento. De fato, a compra de quantidades maiores contribuiria para a redução do preço das mercadorias ao consumidor e no tempo de permanência das mercadorias nas lojas, uma estratégia que os concorrentes ainda não tinham percebido. A solução encontrada foi a compra de uma financeira, desta forma, a rede teria condições de elevar o crédito para as vendas a prazo e também investir em novas lojas. Assim, em 1970, as Casas Bahia adquiriu 50\% da Intervest do armênio Bedros Mikaelian e quatro meses depois os outros 50\% (Awad 2005:118). Na década de 1980, as Casas Bahia adquiriu uma segunda financeira, a "Símbolo". 
O importante era não mudar core business e, para tanto, os investimentos eram direcionados a negócios que ajudassem a empresa a ampliar suas vendas. A primeira aquisição das Casas Bahia foi a "Lojas Piratininga", que tinha três pontos de venda. A estratégia era saturar o mercado periférico antes de entrar na área central de São Paulo. Para isso abriu lojas em Mauá, São Bernardo do Campo e Diadema, na região do ABCD paulista. Em 1972, expandiu os negócios para a Baixada Santista com a aquisição da "Loja da Cidade" e das "Lojas Discopa". A expansão alcançou novas cidades da baixada santista como Cubatão, Vicente de Carvalho e Praia Grande. A ampliação dos negócios alterou a estratégia de comercialização exigindo que parte dos investimentos fosse destinada à publicidade. As campanhas publicitárias passaram a ser realizadas na forma de parcerias com fornecedores, que repassavam 3\% do valor dos pedidos em mercadorias para sua divulgação (Awad 2005:120-29).

A empresa manteve as vendas externas, mas alterou a forma de pagamento. O consumidor comprava a mercadoria do vendedor externo, mas precisava se deslocar até uma loja das Casas Bahia para realizar o pagamento do financiamento. A presença do cliente todo mês nas lojas criou um fluxo favorável para a realização de novas vendas (Awad 2005: 135).

O pagamento de salários acima da média de mercado resultou em trabalhadores mais integrados à atividade da empresa. $\mathrm{O}$ reflexo dessa estratégia pode ser visto no atendimento ao cliente, uma das atividades mais importantes do setor varejista. Um atendimento diferenciado significava o retorno dos consumidores às lojas. A facilidade de identificar oportunidades e empreender novos métodos na atividade varejista é uma característica marcante em Samuel Klein.

Além das estratégias nas vendas, Samuel Klein utilizou o fato de ser o único acionista das Casas Bahia como vantagem em relação aos concorrentes, no sentido de não perder tempo em discussões, caracterizando a firma como empresa familiar. Para garantir a permanência desta característica no grupo, o empreendedor deu prosseguimento à ocupação dos principais postos de comando por representantes da família. Além da mulher, Ana, nomeada vice-presidente, os filhos Michael, Saul e Eva foram incorporados aos principais postos, cada um assumindo, respectivamente, a área financeira, a comercial e o setor de confecções. Mesmo assim, Samuel permaneceu como o principal dirigente e aquele que tomava as decisões finais (Awad 2005:140-43).

A rede cresceu rapidamente na década de 1970 e chegou à marca de 40 lojas em São Paulo, sem alterar sua filosofia em relação aos colaboradores. Um novo incentivo foi instituído com a premiação para a loja que atingisse a cota de vendas estimada no mês. O prêmio era um carro novo que seria comercializado e os recursos distribuídos entre todos os fun- 
cionários da loja, independentemente do cargo exercido. Também começou a pagar no mês de janeiro um décimo quarto salário a todos os funcionários, ação adotada na década de 1970 (Awad 2005:141-43).

Observam-se, novamente, os elementos característicos do empresário schumpeteriano presentes nas decisões de Samuel Klein. Em diversos momentos, os caminhos tomados pela empresa são contrários às ações dos concorrentes. Contudo, esse comportamento em "levar a cabo novas combinações" (Schumpeter 1982:56) se mostrou a melhor alternativa no futuro para as Casas Bahia.

\subsection{Década de 1980-1990: crises, planos de estabilização econômica e crescimento das Casas Bahia}

A década de 1980 foi marcada pelos impactos do segundo choque do petróleo e pela ampliação dos desequilíbrios na balança de pagamentos brasileira. As fontes externas de empréstimos tinham sido reduzidas, devido à redução da liquidez internacional decorrente da elevação da taxa de juros norte-americana. Diante dessa situação, o Presidente João Figueiredo adotou políticas direcionadas à redução da demanda interna para que as exportações se tornassem mais atraentes (Abreu 1989). Apesar desta conjuntura desfavorável, as Casas Bahia continuava a apresentar elevadas taxas de crescimento.

Na primeira oportunidade que teve, Samuel Klein comprou uma fábrica de móveis (Bartira) para fornecer produtos a preços de custo, repassando a redução aos consumidores. Em seguida, incorporou à fábrica de móveis Bartira a Móveis Bela Vista. Em 1981, as Casas Bahia comprou uma rede de 20 lojas com a bandeira "Columbia" que estava presente entre a capital e a região da grande São Paulo. Somente após a saturação do mercado paulista é que as Casas Bahia partiu para outros estados (Awad 2005:140-46).

Os planos de estabilização econômica que foram implementados pelo governo brasileiro sempre representaram possibilidades de crescimento para as Casas Bahia. Durante o "Plano Cruzado", idealizado pelo ministro da Fazenda Dílson Funaro, no governo Sarney, todos os preços foram congelados, implicando na escassez de produtos no mercado. $\mathrm{O}$ plano previa a reforma monetária, a qual incluiu a mudança da moeda de "cruzeiro" para "cruzado". O controle dos preços incorreu na configuração de distorções entre os preços relativos da economia. Esse desequilíbrio resultou na redução de mercadorias disponíveis no mercado. Samuel Klein, ao perceber essa fragilidade no plano, procurou antecipar-se aos concorrentes adquirindo 17 mil refrigeradores. As demais empresas do setor não acreditavam na recuperação das vendas no 
curto prazo. No decorrer do plano, a mudança econômica resultou na recuperação do poder de compra da população, que no curto prazo manifestou-se no retorno dos consumidores às compras. $\mathrm{O}$ resultado foi que em menos de trinta dias todas os refrigeradores foram vendidos (Awad 2005:155-57). A visão diferenciada do empresário diante das possibilidades oferecidas pelo ambiente econômico o destaca em meio aos concorrentes e aos demais indivíduos na economia.

A seqüência de planos econômicos obrigou Samuel Klein a mudar algumas de suas estratégias a fim de ampliar as vendas. Depois de uma reunião com a diretoria, decidiu parcelar as vendas em três pagamentos sem juros. As ações adotadas pelas Casas Bahia foram exatamente contrárias às previsões dos especialistas do mercado varejista e do próprio setor. Essa postura destaca novamente a capacidade do empresário em perceber oportunidades de crescimento da firma, ou seja, ampliação do mercado mesmo quando o ambiente não torna explícito o embasamento do investimento. A partir de 1987, quando foi decretada a moratória da dívida externa, a população perdeu a confiança no governo. Essa alteração no comportamento da economia refletiu-se na aceleração da inflação, que alcançou ao final da década de 1980, e início dos anos 1990, $2.751 \%$ ao ano. Apesar deste ambiente econômico, as Casas Bahia continuou a ampliar sua participação no mercado através das aquisições. Em setembro de 1989, Samuel Klein negociou a compra da rede de lojas "Tamakavi" do empresário Silvio Santos. Outra vez, a agilidade possibilitada pelo fato da empresa ser familiar, que contribui para uma rápida tomada de decisões, fez com que as Casas Bahia se antecipasse aos concorrentes nesta aquisição. No final da década de 1980, a rede contava com mais de cem lojas, metade espalhada nas cidades da grande São Paulo, algumas em Santos e as restantes espalhadas em cidades do interior paulista com mais de cem mil habitantes (Awad 2005:157-58).

Outro momento, foi quando o então Presidente da República Fernando Collor de Melo, implementou o "Plano Collor", que confiscou parte dos ativos da economia. Samuel Klein decidiu neste momento comprar todo o estoque da Philco (que havia decretado férias coletivas), composto por mais de 60.00o aparelhos. Uma alteração no decorrer do plano fez a população retomar o consumo ${ }^{11} \mathrm{e}$, de novo, as Casas Bahia conseguiram lucrar com o plano econômico. Contudo, a crise se agravou na década de 1990, abalando as vendas da empresa. Em 1990, o grupo faturou aproximadamente 873 milhões de dólares, no ano seguinte 618 milhões, em 1992 o faturamento foi de 353 milhões e 1993 aumenta para 383 milhões. A rede mantinha nesta época cerca de 100 lojas, e a

11 No início do Plano Collor houve uma redução da taxa de crescimento da oferta de moeda de $14 \%$ em relação ao PIB para $2 \%$, no entanto, no mês seguinte o governo elevou a oferta de moeda por vários meios a 14\% em meados de maio (Bresser \& Nakano 1991:101-106). 
brusca redução no faturamento obrigou a dispensa de cerca de $35 \%$ dos funcionários, o que equivalia a 3.500 empregados (Awad 2005:16064).

O "Plano Real" implementado em julho de 1994 foi um dos responsáveis pela recuperação no faturamento da empresa. A nova fase que a economia brasileira estava atravessando contribuiu para a ampliação das Casas Bahia, que em pouco tempo triplicou o número de lojas. O crescimento da década de 1990 não alterou a filosofia da empresa, que nunca aceitou a terceirização de serviços, sobretudo na entrega das mercadorias. De acordo com as orientações do grupo, para ter um serviço de qualidade era necessário que os empregados estivessem satisfeitos e com salários acima da média do mercado, o que não seria possível com a terceirização (Awad 2005:165-69).

O profissional do varejo tem que estar sempre bem informado, ou seja, conhecer o que tem em mãos para oferecer ao mercado. Para atingir o objetivo de interligar e interagir com toda a rede, as Casas Bahia investiu na criação de um Sistema de Processamento de Dados (CPD) (Awad 2005:173). A implantação do CPD representava, segundo um estudo do Professor Prahalad (2003), a manutenção dos três princípios básicos das Casas Bahia: i) produtividade, ii) baixo custo nas operações e iii) a satisfação dos clientes. O estudo apontou que em 1994 os concorrentes estavam instalando seus sistemas de processamentos de dados, enquanto as Casas Bahia atualizava os dela. Destaca ainda que a tecnologia tem sido a chave para o crescimento da empresa. O investimento em sistemas informatizados colocou as Casas Bahia como um dos dez maiores clientes e consumidores da IBM do Brasil, que passou a criar softwares específicos para as Casas Bahia (Awad 2005:173).

A expansão da rede pela capital e interior paulista, exigiu investimentos em estrutura, ou seja, a construção ou compra de um depósito para distribuição das mercadorias. Diante desse novo desafio, a política das Casas Bahia passou a ser a centralização de todo o estoque num grande depósito. Em 1994, com quase 100 lojas, o depósito que ficava no interior paulista e tinha 55 mil metros quadrados não suportava o ritmo de crescimento da rede. Pensando no potencial de expansão, o grupo decidiu comprar uma grande área na Via Anhanguera com aproximadamente 800 mil metros quadrados. Pouco tempo depois, conseguiu agregar ao terreno uma nova área que ampliou para 1 milhão de metros quadrados. No que se refere ao transporte das mercadorias, as Casas Bahia renova a frota de caminhões (Awad 2005:174-75) ${ }^{12}$. De acordo com o estudo do professor Prahalad (2005), a empresa se diferencia, ainda, dos concorrentes pela ênfase dada ao processo de negociação

12 Em 2003, a frota correspondia a mais de mil veículos da marca Mercedes-Benz. 
com fornecedores. A firma busca realizar a compra de grandes quantidades de mercadorias, e para isso precisa ter um centro de distribuição eficiente.

No final de 1996, a fim de aumentar sua credibilidade no mercado, Samuel Klein fez uma parceria com o Unibanco para ajustar a defasagem no capital de giro da empresa. Para viabilizar o processo, foi estruturada pelo banco uma operação de debêntures em torno de 250 milhões de dólares e com taxa pré-fixada. As debêntures foram emitidas tendo como garantia as prestações dos clientes que compravam via carnê. Esta operação pode ser colocada em prática com a ajuda da criação da "Bahia Trust” que comprava os recebíveis das Casas Bahia. A combinação de recursos ${ }^{13}$ disponíveis no mercado para captação de empréstimos a juros menores destaca novamente as capacidades do empresário. Enquanto seus concorrentes (Mesbla e Mappin) estavam perdendo mercado, as Casas Bahia buscava alternativas para continuar expandindo, fato que levou a firma a terminar o ano de 2000 com mais de 300 lojas (Awad 2005:179-83).

\subsection{As Casas Bahia e o empresário no século XXI}

O século XXI inaugurou uma nova fase para as Casas Bahia. Em primeiro lugar, pela liderança absoluta no mercado varejista de eletroeletrônicos e, em segundo lugar, pela complexidade a que chegou a administração da empresa. Para Schumpeter, o empresário perde suas características de inovador assim que tiver montado o seu negócio e/ou quando se dedicar a dirigi-lo como outras pessoas dirigem seus negócios (Schumpeter 1982:56).

Em 2002, a empresa implantou uma nova linha de crédito no mercado varejista de eletroeletrônicos, passando a aceitar cartões de crédito tanto à vista quanto a prazo $^{14}$. Neste mesmo ano, adotou o financiamento em 10 vezes sem juros para os consumidores que não possuíam cartões de crédito (Awad 2005:193).

Os investimentos realizados na década de 1990 em tecnologia da informação resultam em parte na elevação do faturamento da empresa. Enquanto os concorrentes gastavam com sistemas de informação 3\% do faturamento, as Casas Bahia gastava $0,8 \%$. Essa diferença percentual está relacionada a três características: i) emprega baixo número de funcionários no setor de tecnologia, ii) não utiliza equipamentos terceirizados, e iii) investe recursos próprios em infra-estrutura. Um exemplo disso, foi a parceria que as Casas Bahia fez com a Cisco e a

Os pagamentos a prazo foram estendidos em até 10 parcelas. 
Telefônica para instalar uma rede que conectasse todas as lojas, depósitos e os centros de distribuição (Prahalad 2003). De novo, Samuel Klein utilizou em benefício da empresa de forma inovadora a combinação de recursos disponíveis no mercado. Essa característica resgata a figura do empresário empreendedor diante da complexidade a que chegou a administração da empresa.

As Casas Bahia terminou 2004 como a maior empresa de varejo de eletroeletrônicos do país e com um faturamento de aproximadamente 9 bilhões de reais (Isto É 2005). Assumiu também o posto de maior investidor em propaganda do país, com gastos de 740 milhões de reais/ano (Pereira 2005). Os investimentos não se concentraram somente em marketing, o sistema de distribuição está entre os setores que mais recebeu recursos. Outra estratégia da rede foi a instalação da "Super-Casas Bahia”, no Anhembi e a captação de recursos através de parcerias com instituições financeiras (vide detalhes no Quadro 1).

\section{QUADRO 1. ESTRUTURA DAS CASAS BAHIA: 2004}

\begin{tabular}{|l|l|}
\hline \multicolumn{1}{|c|}{ ESTRUTURA } & \multicolumn{1}{c|}{ SITUAÇ̃̃o em 2oo4 } \\
\hline Lojas & 408 \\
\hline Estados & $\begin{array}{l}\text { São Paulo, Rio de Janeiro, Minas Gerais, Rio Grande do Sul, Paraná, Santa } \\
\text { Catarina, Mato Grosso do Sul, Goiás e Distrito Federal. }\end{array}$ \\
\hline Funcionários diretos & 32.500 \\
\hline Fornecedores & 3.000 \\
\hline Itens comercializados & 7.000 itens em linha, mas catalogados eram mais de 10.00o itens. \\
\hline Produtos eletroeletrônicos & Responsável por 20\% da produção nacional. \\
\hline Número de clientes & 16 milhões cadastrados, dos quais 13 milhões são clientes ativos. \\
\hline Divisão das vendas & $\begin{array}{l}\text { 65\% são eletrodomésticos e eletroeletrônicos, 30\% móveis e 5\% outros itens } \\
\text { (confecção, bicicletas, etc.). }\end{array}$ \\
\hline Formas de pagamentos & $\begin{array}{l}\text { 80\% das vendas são feitas via crediário, 15\% de cartões de créditos e 5\% à } \\
\text { vista. }\end{array}$ \\
\hline Público alvo & $\begin{array}{l}\text { As classes C,D e E, com renda média de 2,5 salários mínimos. Em sua } \\
\text { maioria (60\%) sem carteira assinada. }\end{array}$ \\
\hline Parcerias financeiras & $\begin{array}{l}\text { Acordo firmado com o Banco Bradesco, o contrato permite ao banco } \\
\text { financiar parte da carteira de crédito das Casas Bahia, pelo período de 3 } \\
\text { anos, inclui a liberação de 3 bilhões de reais. }\end{array}$ \\
\hline Últimos empreendimentos & $\begin{array}{l}\text { Em dezembro de 2004 montou uma loja de cerca de 50 mil m² no centro de } \\
\text { Convenções do Anhembi. A loja faturou aproximadamente 50 milhões de } \\
\text { reais. Ficou conhecida como "Super-Casas Bahia". }\end{array}$ \\
\hline Faturamento & $\begin{array}{l}\text { Em 2004, 9 bilhões de reais. Foram comercializados mais de 34 milhões de } \\
\text { itens. }\end{array}$ \\
\hline Frota de caminhões & $\begin{array}{l}\text { Encerrou o ano de 2004 com 2.10o caminhões que realizaram mais de 9,5 } \\
\text { milhões de entregas. }\end{array}$ \\
\hline Inadimplência & Chega a 8\%. \\
\hline
\end{tabular}

FONTE: Elaboração dos autores a partir de Awad, 2005.

Em Jundiaí-SP a empresa tem um centro de distribuição com um milhão de metros quadrados, que responde por $80 \%$ das operações. Outro centro está localizado em Pavuna (RJ) com 100 mil metros quadrados e também conta com outros seis entrepostos em Belo Horizonte, Goiânia, Brasília, Ribeirão Preto, Campo Grande e Curitiba. 
As Casas Bahia abriu em 2004 uma superloja ocupando os $52.000 \mathrm{~m}^{2}$ do parque Anhembi em São Paulo. Durante o mês de dezembro de 2004, a loja alcançou o faturamento de 50 milhões de reais, e mais 1,2 milhão de pessoas visitaram o local (Carvalho 2004).

A parceria entre as Casas Bahia e o Bradesco, na qual o banco passou a ter exclusividade nos financiamentos aos consumidores da empresa pelo período de três anos, foi a alternativa para financiar o crescimento. Essa parceria envolveu o volume de três bilhões de reais em três anos. As Casas Bahia têm um plano arrojado de expansão e para isso recorreu a recursos externos que lhe permitiram concentrar-se no crescimento da rede. As Casas Bahia financia cerca de $80 \%$ de suas vendas, o que significa uma carteira de crédito de 4,5 bilhões de reais, considerando as vendas de seis bilhões de reais em 2003. A maior parte da carteira é financiada com recursos próprios e apenas 1 bilhão de reais são captados no mercado financeiro. Pelo acordo, o banco assumirá o financiamento de pelo menos 100 milhões de reais em vendas por mês e a expectativa é chegar a três bilhões em um ano. A previsão para 2005 é de um aumento de mais $25 \%$, levando as vendas para a marca de 10 bilhões de reais (Carvalho 2004).

As novas estratégias adotadas pelas Casas Bahia ampliaram a distância dos concorrentes, não apenas no faturamento, mas em tamanho, estrutura logística, investimentos em propaganda e na taxa de crescimento. Essa postura seguida na gestão da empresa, desde os tempos que Samuel Klein era mascate, sugere a presença do empresário inovador em diferentes momentos da firma. Aquele agente que se diferencia dos demais indivíduos, coloca a cabo novas combinações no mercado.

\section{Conclusão}

A teoria schumpeteriana se concentra na inovação tecnológica e na indústria manufatureira, sendo poucos os textos disponíveis na literatura vinculados ao setor de serviços, numa forma mais particular o comércio. O empresário schumpeteriano mostra como determinados agentes econômicos podem se diferenciar de outros indivíduos, o que ocorre em todos os setores da economia.

O estudo realizado neste trabalho apresentou como ponto de partida a revisão da literatura sobre os aspectos que caracterizam uma inovação e o empresário schumpeteriano. De acordo com Schumpeter (1982 1984), inovação significa a ação de empreender novas combinações dos materiais e forças produtivas disponíveis na economia, com o objetivo de viabilizar a produção de novas mercadorias ou uma nova maneira de 
prestar um serviço ${ }^{15}$. O empresário assume o papel central no processo de inovação, ele é o agente que consegue por meio dos recursos disponíveis no mercado colocar a cabo as novas combinações (Schumpeter 1982:56).

O objetivo deste estudo foi identificar na figura de Samuel Klein, a presença de elementos que o caracterizem como um empresário schumpeteriano. Para isso foi apresentada a história das Casas Bahia e do fundador sob a perspectiva econômica. Durante as fases de crescimento da empresa, diversas situações e atitudes do empresário destacaram alguns elementos definidos na teoria schumpeteriana.

As características de empresário inovador, logo se manifestaram em Samuel Klein na sua primeira atividade comercial em território brasileiro. No exercício da atividade de mascate, conseguiu identificar as possibilidades, empreender novas combinações dos recursos disponíveis para diferenciar-se no mercado. A aquisição da primeira loja foi outro ponto marcante no desempenho da função de empresário, empreendimento que ampliou as oportunidades de gerar novas combinações. A primeira foi através da abertura de novos mercados, acompanhada da elevação da capacidade de negociação e, por último, os investimentos em tecnologia da informação, onde podem ser incluídos os investimentos em sistemas de informação e publicidade.

Segundo Schumpeter, o empresário para inovar não precisa ser proprietário do capital. Esse elemento ficou claro na gestão da empresa analisada pois, quando a escassez de recursos impedia novos investimentos e empreendimentos, o empresário buscou criar uma fonte própria de recursos, adquirindo financeiras e, em outros casos, procurou parcerias com instituições bancárias. Conclui-se, portanto, que as características definidas por Schumpeter (1964, 1982 e 1984) podem ser identificadas no empresário Samuel Klein.

A mudança na direção da empresa na qual assume o filho mais velho Michael Klein não foi englobada neste trabalho. Desta maneira, pode ser interessante empreender um novo estudo para verificar se o sucessor apresenta os elementos característicos do empresário fundador, uma vez que, de acordo com a teoria schumpeteriana, a função de empresário inovador não pode ser herdada.

15 Relacionado à atividade comercial que, segundo Schumpeter (1982:49), é capaz de empreender algum tipo de inovação no mercado. 


\section{Referências}

ABREU, M. (1989). A ordem do progresso: 100 anos de política econômica na República. Rio de Janeiro: Campus.

AWAD, E. (2005). Samuel Klein e Casas Bahia: uma trajetória de sucesso. 2. ed. São Paulo: Novo Século.

BÊRNI, D. \& CORRÊA, D. (2005). "O conceito de empresário empreendedor schumpeteriano e sua atualização.” URL: http://www.pucrs.br/uni/poa/ face/eco/text_dsc/duconcei.pdf. Acesso em: 02 de maio de 2005.

BNDES (1996). “Comércio Varejista.” URL: http://www.bndes.gov.br/ conhecimento/relato/com_vare.pdf. Acesso em: 02 de maio de 2005.

(2005). "Comércio especializado de eletroeletrônicos." URL: http:// www.bndes.gov.br/conhecimento/setorial/get2is18.pdf. Acesso em: 02 de maio de 2005.

BRESSER, L. \& NAKANO, Y. (1991). "Hiperinflação e estabilização no Brasil: o primeiro Plano Collor.” Revista de Economia Política 11(4):89-114.

CALAZANS, R. A. (1992). "Lógica de um discurso: o empresário schumpeteriano." Ensaios FEE 2:640-67.

CARVALHO, M. (2004) "Casas Bahia e Bradesco fecham parceria no crédito." URL: www.bancariosdf.com.br/.../bancos_privados/2004/11_nov/ Casas_Bahia_e_Bradesco_fecham_parceria_no_credito.htm. Acesso em: o5 de maio de 2005.

COASE, R. (1937). "The nature of the firm.” Economica 4:386-405.

EKERMAN, R. \& ZERKOWSKI, R. (1984). “A análise teórica schumpeteriana do ciclo econômico." Revista Brasileira de Economia 38(3):205-28.

FELTRIN, A. (2005). "Casas Bahia investe R\$ 30 milhões em novo centro de distribuição." Gazeta Mercantil on line, 14 de março. URL: www.gazetamercantil.com.br. Acesso em: 05 de maio de 2005.

FGV (2003). "Impactos verticais da concentração do setor varejista brasileiro." URL: http://www.fiesp.com.br/download/palestras/ pesquisavarejo.pdf. Acesso em: 02 de maio de 2005.

GAZETA Mercantil (2004). São Paulo, 15 de setembro de 2004.

IBGE (2004). "Pesquisa Mensal de Comércio." URL: http://www.ibge.gov.br/ home/presidencia/noticias/notapmc.shtm. Acesso em: 15 de maio de 2005 .

ISTO É, DINHEIRO (2005). “Michael Klein por Isto é, Dinheiro.” URL: h t t p : / / gazetaonline.globo.com / marketing place/ entrevista.php?id_entrevista=21. Acesso em: 05 de maio de 2005.

MARSHALL, A. (1985). Princípios de economia. São Paulo: Nova Cultural, coleção Os Economistas.

NOGUEIRA, H. (1988). "Observações sobre a mudança tecnológica em Schumpeter.” Estudos Econômicos 18(3):433-48. 
PADILHA, M. (2004)."Expansão do crédito impulsiona vendas." Gazeta Mercantil, 14 de setembro de 2004, p. A-10.

PANORAMA SETORIAL (2005). "Cadeia do Setor de eletrodomésticos." URL: http://www.panoramasetorial.com.br/materia/pontodevista.asp?id=4. Acesso em: 05 de maio de 2005.

PAULA, J. A. et al. (2004). “Teoria econômica, empresários e metamorfoses na empresa industrial." URL: www.cedeplar.ufmg.br/pesquisas/td/ TD\%20133.doc. Acesso em: 02 de maio de 2005.

PENROSE, E. (1995). The theory of the growth of the firm. Nova Iorque: Oxford.

PEREIRA, E. (2005). "Bahia de todas as mídias, Associação de Mídia Interativa." URL: http://site.ami.org.br/bnews3/images/multimidia/ pdf/Ranking\%202003\%20-\%20Anunciantes.pdf. Acesso em: 05 de maio de 2005 .

PRAHALAD, C. (2005). "Casas Bahia fulfilling a dream.” URL: http:// www.bus.umich.edu/BottomOfThePyramid/xMAP2003.htm. Acesso em: 17 de maio de 2005 .

POSSAS, M. (1987). A dinâmica da economia capitalista: uma abordagem teórica. São Paulo: Brasiliense.

SCHUMPETER, J. (1964). Business cycles - a theoretical, historical and statistical analysis of the capitalist process. Nova Iorque: Porcupine Press. tural.

(1982). A teoria do desenvolvimento econômico. São Paulo: Nova Cul(1984). Capitalismo, socialismo democracia. Rio de Janeiro: Zahar.

Recebido em: 22 nov. 2005

Aceite em: 30 abr. 2006 